\title{
Scour potential at Laouzas Dam
}

\author{
E. Bollaert \\ AquaVision Engineering, Ecublens, Switzerland
}

F. Morel \& B. Blancher

EDF-DPIH, Centre d'Ingénierie Hydraulique, Le Bourget du Lac, France

P. Lucquiaud

EDF-CEIDRE, Service Géologie Géotechnique, Aix-en-Provence, France

\begin{abstract}
Laouzas Dam, owned and operated by Electricité de France (EDF), is a $52 \mathrm{~m}$ high doublecurvature arch dam in a large valley located on the Vèbre River in the Languedoc-Roussillon Midi Pyrénées region of France. The dam is founded on heavily fractured granite and migmatite rock. It houses a surface spillway equipped with 3 radial gates. The radial gates are positioned such that their gate lip is systematically located about $1 \mathrm{~m}$ upstream of the spillway crest itself. This particular design generates aerated jets that do not behave like normal falling jets. Despite the absence of severe spillages since dam construction in 1961-1965, the ones observed in the past have allowed creating locally a $5 \mathrm{~m}$ deep scour hole along the right hand side of the rock mass. The granite and migmatite have significant unconfined compressive strength. The rock mass fracturing is composed of 3-4 joint sets and shows desquamation joints affecting both abutments. EDF has commissioned a numerical study to assess scour potential downstream of the dam as well as the positive influence of rock anchors, by using the Comprehensive Scour Model (CSM).
\end{abstract}

\section{INTRODUCTION}

Laouzas Dam, owned and operated by Electricité de France (EDF), is a $52 \mathrm{~m}$ high double-curvature arch dam located in a large valley on the Vèbre River in the Languedoc-Roussillon Midi-Pyrénées region of France, just north of the city of Béziers (Fig. 1). The dam is founded on granite (erodability index rated at 2140) and migmatite rock. It houses a surface spillway equipped with three radial gates. The radial gates are positioned such that, when functioning, their gate lip is systematically located about $1 \mathrm{~m}$ upstream of the spillway crest itself (Fig. 2). This particular design was selected during construction to avoid a downstream overhanging superstructure and to allow the roadway to pass the dam crest without being obstructed by the gate pivot bearings or by gate openings. It generates aerated jets that do not behave like normal jets.

Despite the absence of severe spillages (priority to bottom valve, and reservoir management to avoid spilling and maximize power generation) since dam construction in 1961-1965, the ones observed in the past have allowed creating a $5 \mathrm{~m}$ deep scour hole along the right hand side of the downstream rock mass (Fig. 2). The granite and migmatite downstream of the dam have significant unconfined compressive strength. The rock mass fracturing is composed of 3-4 joint sets, and shows desquamation joints affecting both abutments. EDF has commis- sioned a numerical study to assess any further scour potential downstream of the dam.

The computations have been made by the Comprehensive Scour Model (CSM). This model allows predicting rock scour potential with time based on a series of rock break-up mechanisms (rock mass fracturing, rock block uplift and rock block peeling off). The predictions have been soundly calibrated based on past spillages and scour observations at the site.

This paper presents the outcomes of the numerical study. It specifically focuses on the potential for regressive scour towards the toe of the dam as well as on the potential beneficial influence of a series of 132 passive rock anchors that have been sealed into the rock mass, about $6 \mathrm{~m}$ deep, in the areas susceptible to be damaged by the falling jet.

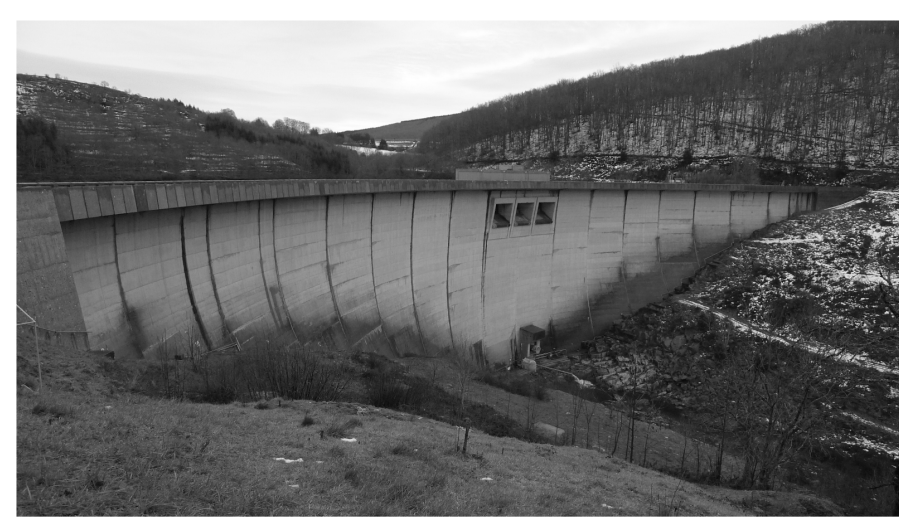

Figure 1. Aerial view of Laouzas Dam. 

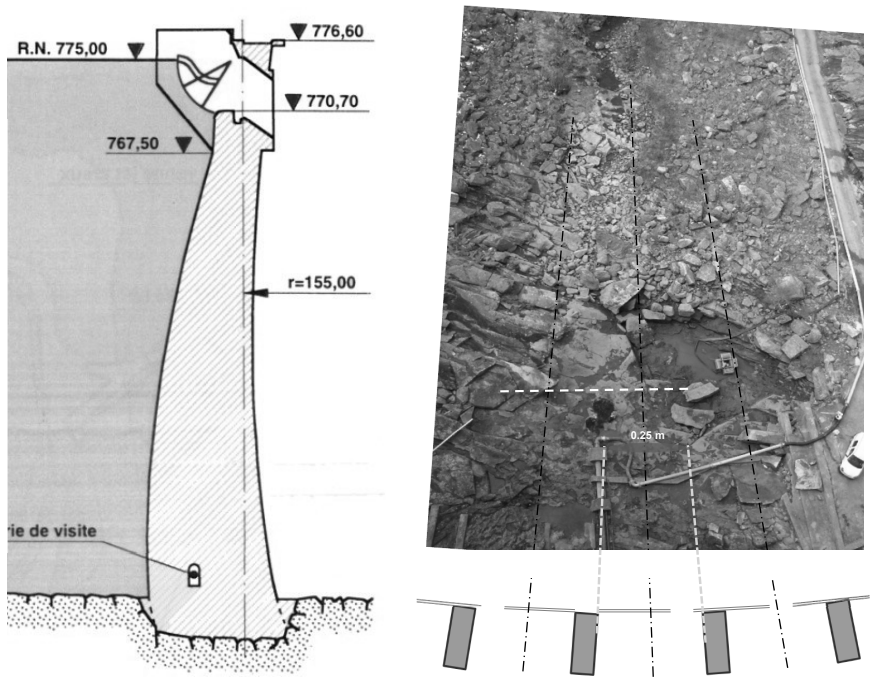

Figure 2. Sectional view and plunge pool of Laouzas Dam.

\section{MAIN PARAMETERS}

\subsection{Historic spillway functioning}

The history of spillway functioning (annual tests to assess functioning of spillway and bottom gates excepted) has been made available by EDF for each of the three gates for the period 1965-2014. During this period, the most important discharge is $62.5 \mathrm{~m}^{3} / \mathrm{s}$ (1996 flood), i.e. far less than a 10-year flood max. discharge of $\sim 190 \mathrm{~m}^{3} / \mathrm{s}$ (HQ10).

Figure 3 illustrates the history of the spilled water volumes for each of the gates, as well as the max. gate opening during spilling. Gate openings thereby do not follow any rules. It can be observed that gate 2 (center), which is now used in priority, has spilled twice as much as gate 3 (right bank) and 4 times as much as gate 1 (left bank). The main reason can be found in the 1995-1996 flood event, during which gate 2 openings were much higher than usual, with a max. of $1.45 \mathrm{~m}$ and an average opening of $0.70 \mathrm{~m}$.

Gate 3 (right bank) has been mainly used during the 1982 and 1996 flood events, during which the main scour hole has been formed.

Gate 1 (left bank) has been mainly used in the 1960's and 1970's, and shows average/max. openings and total overflow volumes that are quite similar to gate 3 on the right bank.

Figure 4 shows historical flow durations as a function of gate openings for each gate separately. Gate 1 on the left bank has exhibited much less important flow durations than the other two gates.

As shown in Fig. 2, the scour hole has historically developed along the right bank, under gates 2 and 3, and not along the left bank, under gate 1 . This might be due to the higher water volumes discharged, or also the longer flow durations.

It might also indicate that scour vulnerability is higher in the rock mass along the right bank than along the left bank. This is discussed in $\S 2.3$.

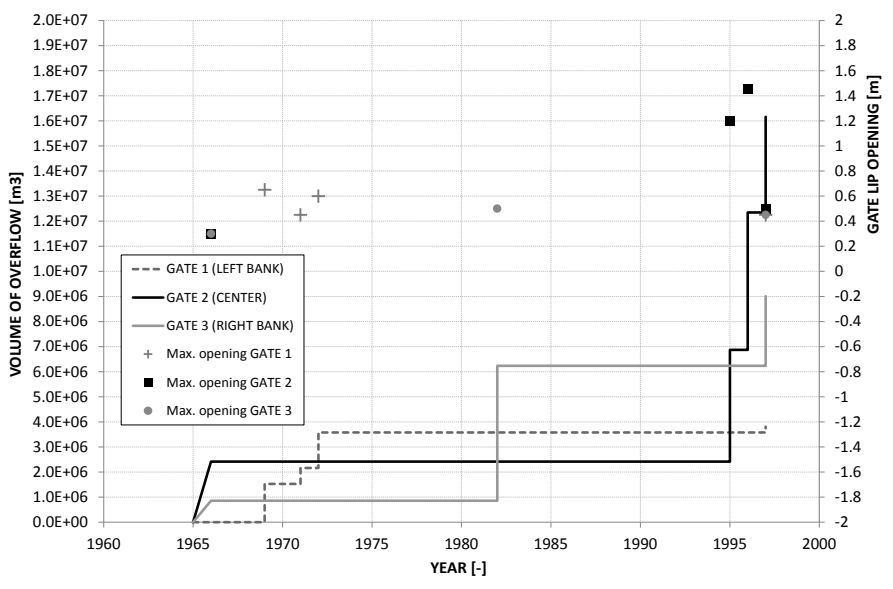

Figure 3. Spilled volumes and max. gate openings at Laouzas Dam (per gate).

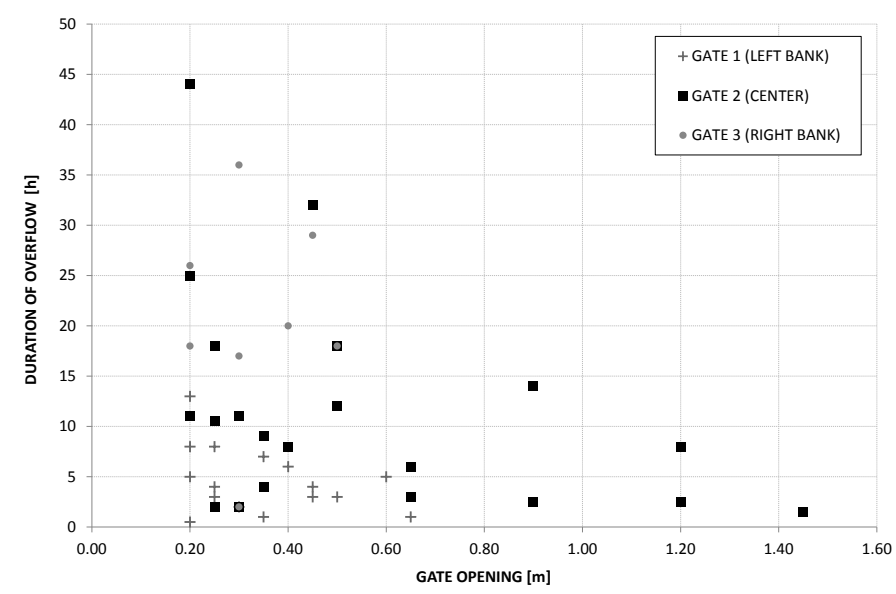

Figure 4. Flow durations as a function of gate opening at Laouzas Dam (per gate).

\subsection{Hydrodynamic parameters}

Figure 5 illustrates the trajectory and shape of the jets issuing from the gates. The jets remain rectangular during their fall, with relatively low aeration. They remain compact upon impact and have low initial turbulence intensity at all openings ( $\sim 1-2 \%)$.

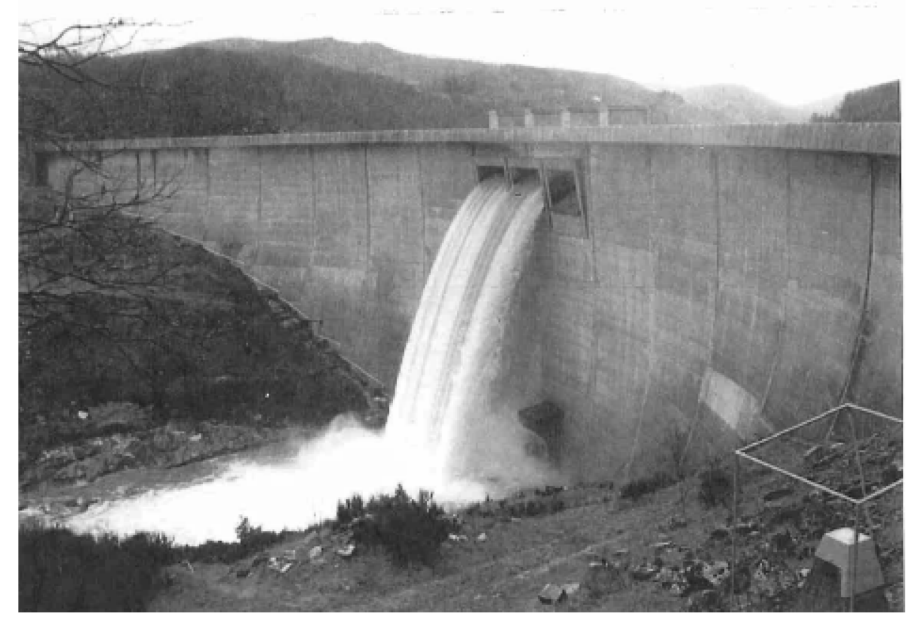

Figure 5. Aerial view of jet trajectories at low discharges. 
Furthermore, the impact points of the jet footprint upon the downstream rock mass do not coincide with usual theoretical computations based on ballistics and air drag. This is due to the particular design of the gates, which are located about $1 \mathrm{~m}$ upstream of the spillway crest, needed for sound integration of the roadway just behind the gates.

Figure 6 illustrates the corresponding jet trajectories compared to conventional trajectories as measured on the Grangent Dam geometry, a similarshaped dam for which physical model studies have been performed before dam construction. The crest and spillway gates of Laouzas Dam have been added to these trajectories for sake of comparison.

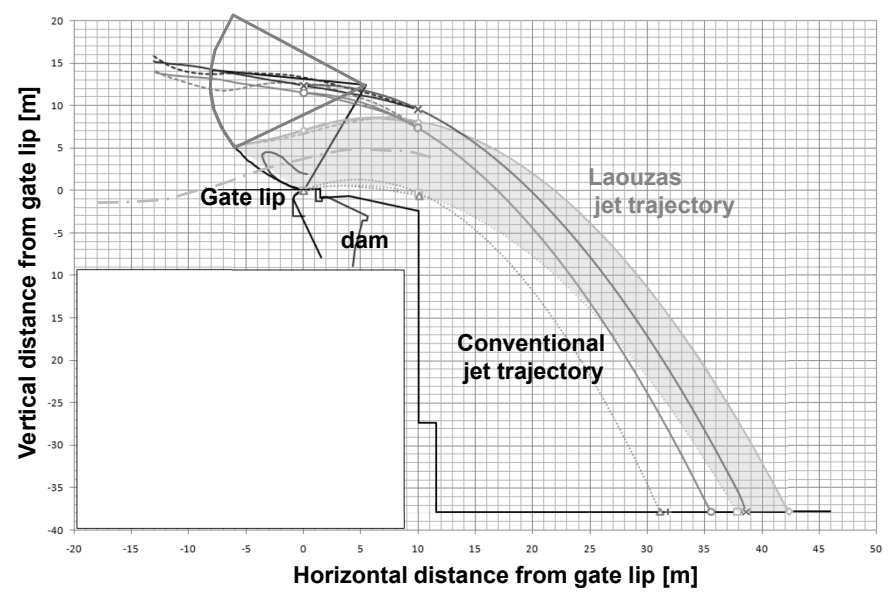

Figure 6. Sectional view of particular gate design and jet trajectories as measured on Grangent Dam physical model.

\subsection{Geomechanic parameters}

The rock mass downstream of the dam is a mixture of granite and migmatite, showing desquamation along both river banks, oriented at about $20^{\circ}$ with horizontal towards the center, from the plunge pool surface down to depths of about $2 \mathrm{~m}$ along the left side and down to depths of 5-6 $\mathrm{m}$ along the right side of the plunge pool (Figure 7).

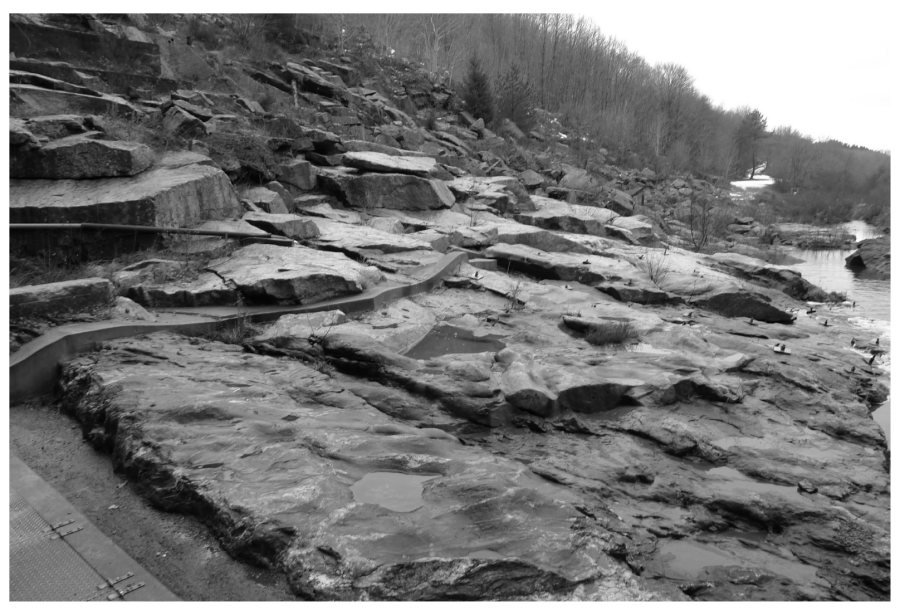

Figure 7. View of rock mass and desquamation along left hand side of plunge pool.
The rock generally exhibits 3 vertical joint sets and 1 sub-horizontal joint set, with mainly plane and closed joints without infilling. Joint spacing is estimated at 1-2 $\mathrm{m}$ on the average. Joints seem completely formed at the surface. Typical rock block shapes are flat with a height-to-side-length ratio of about 1:4 (Figure 7).

Based on a series of borehole tests performed in 2013, the UCS (Unconfined Compressive Strength) values are about $100 \mathrm{MPa}$ along the left hand side of the plunge pool, and up to $150-200 \mathrm{MPa}$ along the right hand side. The center of the plunge pool has UCS values of 120-140 MPa.

Figure 8 illustrates the variability of UCS strengths with depth along 3 main boreholes situated in the center and along left and right hand sides of the plunge pool. It also presents the presence and interdistance of fissures with depth in the same boreholes.

This illustrates that the right hand side of the plunge pool exhibits jointing with depth, confirmed by low RQD values in fissured areas. The left hand side, however, shows much less jointing with depth, together with high RQD values of up to $80-100 \%$.

Hence, despite a somewhat lower UCS strength, the left hand side of the plunge pool has a much lower vulnerability to scour than the right hand side, because of its very low degree of initial fracturing. A transitional area exists in the center of the plunge pool. This transition from low to high scour vulnerability can clearly be observed in Figure 2.

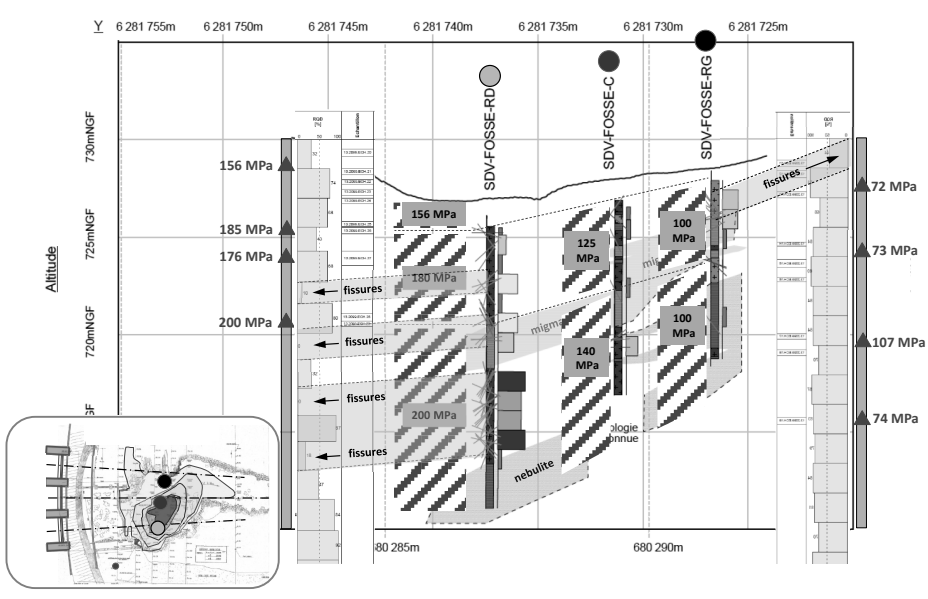

Figure 8 . Sectional and plan view of borehole data. 


\subsection{Hydrologic parameters}

The hydrology at the dam site is illustrated in Fig. 9 for HQ10, HQ100 and HQ1000, together with the corresponding flow duration curve (FDC) and the numerical simplification of the hydrographs into multiple blocks of constant discharge (3 blocks for HQ10, 4 blocks for HQ100 and 6 blocks for HQ1000).
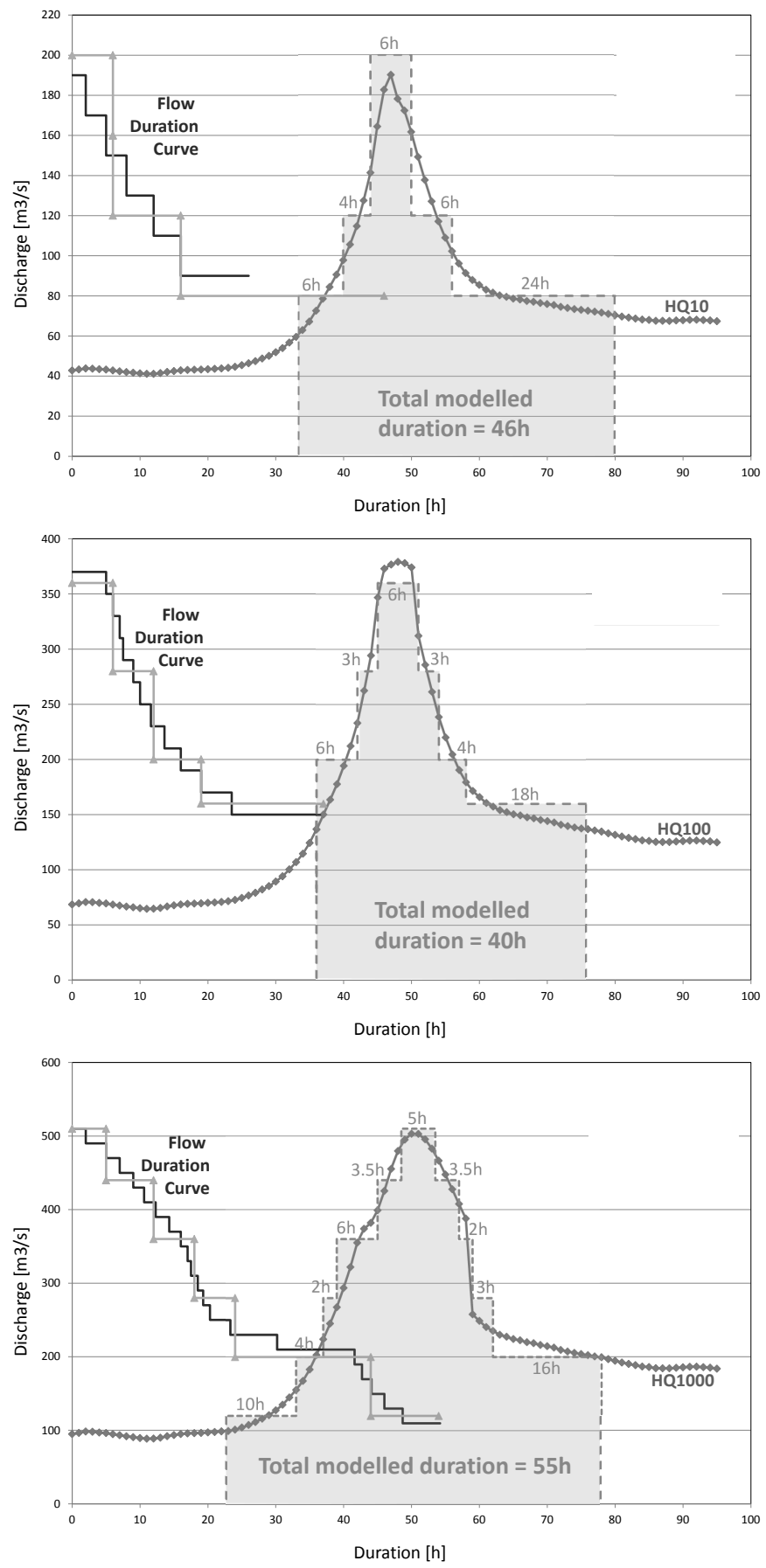

Figure 9. HQ10-HQ100-HQ1000 flood hydrology.

\subsection{Rock anchor parameters}

In 2007, 132 passive rock anchors were installed in the weakest area of the plunge pool, in order to prevent any potential scour regression towards the dam toe. As shown in Figure 10, a total of 132 anchors of $6 \mathrm{~m}$ of total length have been sealed over an area of
$300 \mathrm{~m}^{2}$ (30 $\mathrm{m}$ transverse to $10 \mathrm{~m}$ longitudinal). The average density of the anchors is about $1.5 \mathrm{~m}$ by 1.5 $\mathrm{m}$, with local variations. Steel with an elasticity limit of $500 \mathrm{~N} / \mathrm{mm}^{2}$ has been used, corresponding to a max. force of $402 \mathrm{kN}$ per anchor, as well as a nominal diameter of $32 \mathrm{~mm}$. Anchor plate dimensions were $200 \mathrm{~mm}$ by $200 \mathrm{~mm}$.

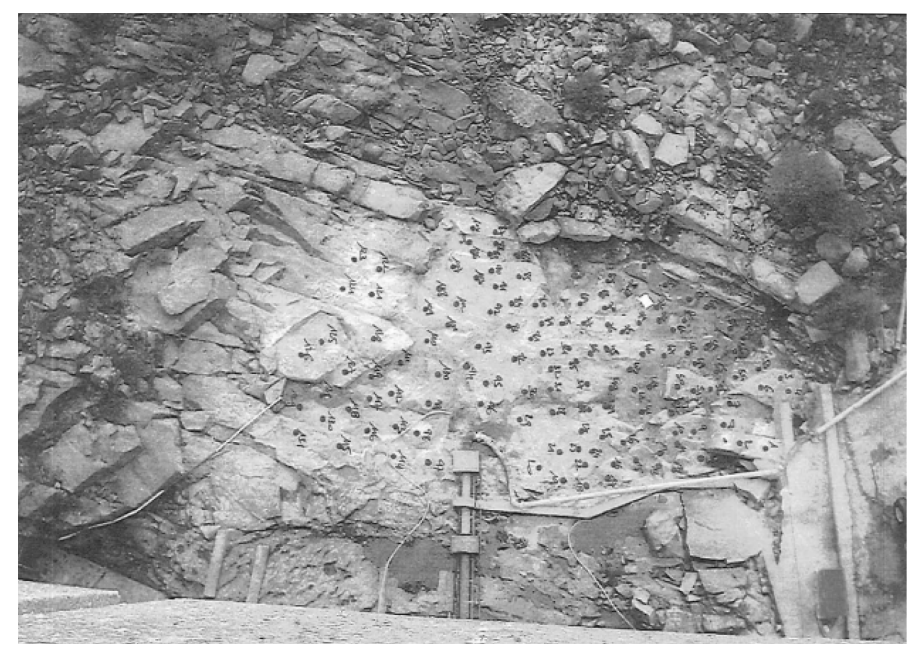

Figure 10. Plan view of 132 rock anchors in plunge pool.

\section{THE COMPREHENSIVE SCOUR MODEL}

The Comprehensive Scour Model comprises three methods that describe failure of jointed rock. The Comprehensive Fracture Mechanics (CFM) method determines the ultimate scour depth by expressing instantaneous or time-dependent joint propagation due to water pressures inside the joint. The Dynamic Impulsion (DI) method describes the ejection of rock blocks from their mass due to sudden uplift pressures. The Quasi-Steady Impulsion Model (QSI) describes peeling off of rock blocks from their mass by quasi-steady wall jet flows.

The structure of the Comprehensive Scour Model consists of three modules: the falling jet, the plunge pool and the rock mass. The latter module implements the aforementioned failure criteria. More details on equations can be found in Bollaert (2004).

\subsection{The module of the falling jet}

This module describes how the hydraulic and geometric characteristics of the jet are transformed from dam issuance down to the plunge pool water level (Fig. 11). Three parameters characterize the jet at issuance: the velocity $\mathrm{V}_{\mathrm{i}}$, the diameter (or width) $\mathrm{D}_{\mathrm{i}}$ (calculated using the upper nappe profile of ogee spillway flow) and the initial turbulence intensity $T_{u}$, defined as the ratio of velocity fluctuations to the mean velocity. The jet trajectory is based on ballistics and air drag but calibrated by in-situ observations because of the particular spillway design. The jet module computes the longitudinal location of im- 
pact, the total trajectory length $\mathrm{L}$ and the velocity and diameter at impact $\mathrm{V}_{\mathrm{j}}$ and $\mathrm{D}_{\mathrm{j}}$.

\subsection{The module of the plunge pool}

This module describes the characteristics of the jet when traversing the plunge pool and defines the water pressures at the water-rock interface. The ratio of water depth to jet diameter at impact $\mathrm{Y} / \mathrm{D}_{\mathrm{j}}$ is directly related to jet diffusion. The most relevant pressures are the mean dynamic pressure coefficient $\mathrm{C}_{\mathrm{pa}}$ and the root-mean-square (rms) coefficient of the fluctuating dynamic pressures $\mathrm{C}_{\mathrm{pa}}^{\prime}$, both measured at the jet centerline. These coefficients correspond to the ratio of pressure head (in $[\mathrm{m}]$ ) to incoming kinetic energy of the jet $\left(\mathrm{V}^{2} / 2 \mathrm{~g}\right)$.

\subsection{The module of the rock mass}

The main parameters of this module are:

1. maximum dynamic pressure coefficient $C_{p}^{\max }$

2. characteristic amplitude of pressure cycles $\Delta \mathrm{p}_{\mathrm{c}}$

3. characteristic frequency of pressure cycles $f_{c}$

4. maximum dynamic impulsion coefficient $\mathrm{C}_{\operatorname{maxI}}$

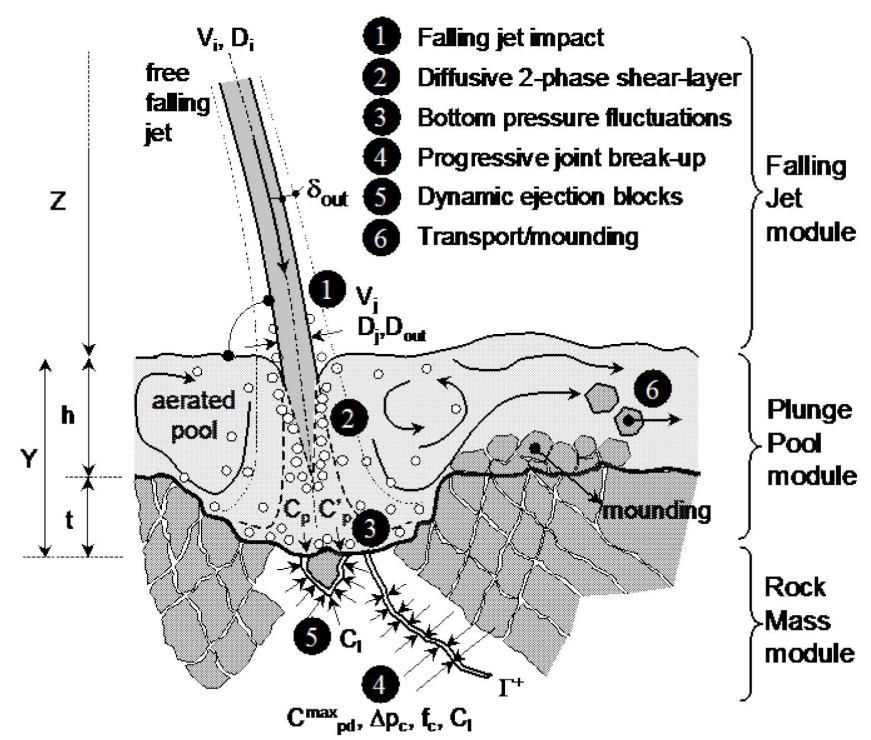

Figure 11: Parameters of Scour Model (Bollaert, 2004)

The first parameter is relevant to brittle propagation of closed-end rock joints. The second and third parameters express time-dependent propagation of closed-end rock joints. The fourth parameter is used to define dynamic uplift of rock blocks formed by open-end rock joints. The maximum pressure $\mathrm{C}_{\operatorname{maxp}}$ is obtained through multiplication of the rms pressure $\mathrm{C}_{\mathrm{pa}}^{\prime}$ with an amplification factor $\Gamma^{+}$, and by superposition with the mean pressure $\mathrm{C}_{\mathrm{pa}} . \Gamma^{+}$expresses the ratio of the peak value inside the rock joint to the rms value of pressures at the pool bottom and has been determined based on prototype-scaled experiments (Bollaert, 2004). The product of $\mathrm{C}_{\mathrm{pa}}^{\prime}$ times $\Gamma^{+}$ results in a maximum pressure, written as:

$$
P_{\max }[P a]=\gamma \cdot C_{p}^{\max } \cdot \frac{V_{j}^{2}}{2 g}=\gamma \cdot\left(C_{p a}+\Gamma^{+} \cdot C_{p a}^{\prime}\right) \cdot \frac{V_{j}^{2}}{2 g}
$$

The characteristic amplitude of the pressure cycles, $\Delta \mathrm{p}_{\mathrm{c}}$, is determined by the maximum and minimum pressures of the cycles. The characteristic frequency of pressure cycles $f_{c}$ follows the assumption of a perfect resonator system and depends on the air concentration in the joint $\alpha_{i}$ and on the length of the joint $\mathrm{L}_{\mathrm{f}}$. These parameters are used by three methods to express rock break-up, they are discussed below.

\section{Fracture Mechanics method}

The cyclic character of pressures generated by jets makes it possible to describe joint propagation by fatigue stresses occurring at the tip of the joint. A simplified methodology (Bollaert, 2004) is called the Comprehensive Fracture Mechanics (CFM) method and applicable to any partially jointed rock. Pure tensile pressure loading inside rock joints is described by the stress intensity factor $\mathrm{K}_{\mathrm{I}}$, representing the amplitude of rock mass stresses generated by water pressures at the tip of the joint. The corresponding resistance of the rock mass against joint propagation is expressed by its fracture toughness $\mathrm{K}_{\mathrm{Ic}}$.

Joint propagation distinguishes between brittle (or instantaneous) and time-dependent joint propagation. The former happens for a stress intensity factor equal to or higher than the fracture toughness. The latter is occurring when the maximum possible water pressure results in a stress intensity that is inferior to the material's resistance. Joints may then be propagated by fatigue. Failure by fatigue depends on the frequency and the amplitude of the load cycles. The fracture mechanics implementation of the hydrodynamic loading consists of a transformation of the water pressures in the joints into stresses in the rock. These stresses are characterized by $\mathrm{K}_{\mathrm{I}}$ as follows:

$K_{I}=P_{\max } \cdot F \cdot \sqrt{\pi \cdot L_{f}}$

in which $\mathrm{K}_{\mathrm{I}}$ is in $\mathrm{MPa} \sqrt{\mathrm{m}}$ and $\mathrm{P}_{\max }$ in $\mathrm{MPa}$.

The boundary correction factor $\mathrm{F}$ depends on the type of crack and on its persistency, i.e. its degree of cracking defined as $\mathrm{a} / \mathrm{B}$ or $\mathrm{b} / \mathrm{W}$ in Figure 12 . This figure presents basic configurations for partially jointed rock. The choice of the most relevant geometry depends on the type and the degree of jointing.

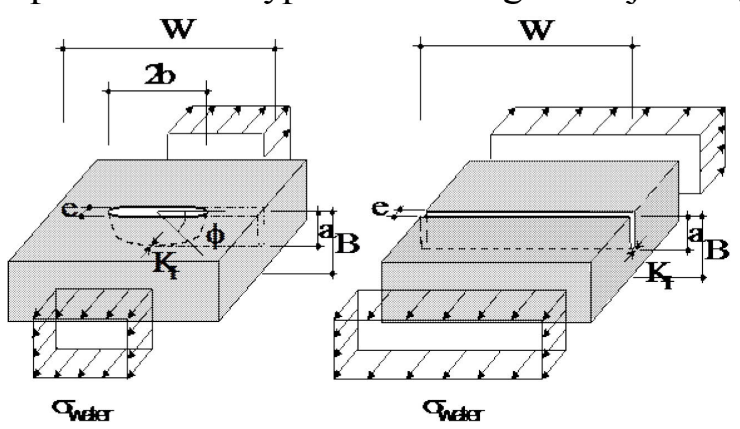

Figure 12: Rock joint configurations of CSM model 
For practice, $\mathrm{F}$ values of 0.5 or higher are considered to correspond to completely broken-up rock. For values of 0.1 or less, a tensile strength approach is more plausible.

The fracture toughness $K_{I c}$ is related to the mineralogical type of rock and to the unconfined compressive strength UCS. Furthermore, corrections are made to account for the loading rate and the in-situ stress field. The corrected fracture toughness is defined as the in-situ fracture toughness $\mathrm{K}_{\mathrm{I} \text {,ins }}$ and is based on a linear regression of available literature data. More detailed equations, as a function of the mineralogical rock composition, can be found in Bollaert (2002).

$K_{\text {lins }, U C S}=(0.008$ to 0.010$) \cdot U C S+\left(0.054 \cdot \sigma_{c}\right)+0.42$

in which $\sigma_{\mathrm{c}}$ represents the confinement horizontal in-situ stress and UCS and $\sigma_{c}$ are in MPa. Timedependent joint propagation is expressed by an equation originally proposed to describe fatigue growth in metals:

$\frac{d L_{f}}{d N}=C_{r} \cdot\left(\Delta K_{I} / K_{I c}\right)^{m_{r}}$

in which $\mathrm{N}$ is the number of pressure cycles. $\mathrm{C}_{\mathrm{r}}$ and $\mathrm{m}_{\mathrm{r}}$ are material parameters that are determined by fatigue tests and $\Delta \mathrm{K}_{\mathrm{I}}$ is the difference of maximum and minimum stress intensity factors. To implement time-dependent joint propagation into the model, $\mathrm{m}_{\mathrm{r}}$ and $\mathrm{C}_{\mathrm{r}}$ have to be known. They represent the vulnerability of rock to fatigue and can be derived from available literature data.

\section{Dynamic Impulsion method}

The fourth dynamic loading parameter is the maximum dynamic impulsion $\mathrm{C}_{\max }$ underneath a rock block, obtained by time integration of the net forces on the block (Newton):

$$
I=\int_{0}^{\Delta t p u l s e}\left(F_{u}-F_{o}-G_{b}-F_{s h}\right) \cdot d t=m \cdot V_{\Delta t p u l s e}
$$

in which $F_{u}$ and $F_{o}$ are the forces under and over the block, $G_{b}$ is the immerged weight of the block and $\mathrm{F}_{\mathrm{sh}}$ represents the shear and interlocking forces.

The first step is to define the maximum net impulsion $\mathrm{I}_{\max }$ as the product of a net force and a time period. The corresponding pressure is made nondimensional by the jet's kinetic energy $\mathrm{V}^{2} / 2 \mathrm{~g}$. This results in a net uplift pressure coefficient $\mathrm{C}_{\text {up }}$. The time period is non-dimensionalized by the travel period that is characteristic for pressure waves inside rock joints, i.e. $\mathrm{T}=2 \cdot \mathrm{L}_{\mathrm{f}} / \mathrm{c}$. This results in a time coefficient $\mathrm{T}_{\text {up }}$. Hence, the non-dimensional impulsion coefficient $\mathrm{C}_{\mathrm{I}}$ is defined by the product $\mathrm{C}_{\text {up }} \cdot \mathrm{T}_{\text {up }}=$ $\mathrm{V}^{2} \cdot \mathrm{L} / \mathrm{g} \cdot \mathrm{c}[\mathrm{m} \cdot \mathrm{s}]$. The maximum net impulsion $\mathrm{I}_{\max }$ is obtained by multiplication of $\mathrm{C}_{\mathrm{I}}$ by $\mathrm{V}^{2} \cdot \mathrm{L} / \mathrm{g} \cdot \mathrm{c}$. Proto- type-scaled analysis of uplift pressures resulted in the following expression for $\mathrm{C}_{\mathrm{I}}$ :

$$
C_{I}=0.0035 \cdot\left(\frac{Y}{D_{j}}\right)^{2}-0.119 \cdot\left(\frac{Y}{D_{j}}\right)+1.22
$$

Failure of a block is expressed by the displacement it undergoes due to the net impulsion $\mathrm{C}_{\mathrm{I}}$. This is obtained by transformation of $\mathrm{V}_{\Delta \text { tpulse }}$ in Eq.(5) into a net uplift displacement $h_{u p}$.

\section{Quasi-Steady Impulsion method}

Finally, the quasi-steady impulsion method (QSI) describes the flow parallel to the bottom, outside of the impingement region of the jet. In case of protruding rock blocks along the bottom, the flow is deflected by these blocks, which generates turbulent pressure fluctuations. In contrast with turbulent wall pressures that are generated by turbulent eddies of the flow itself, these pressure fluctuations are of quasi-steady character (Bollaert \& Hofland, 2004). As such, they generate significant lift and drag forces on protruding rock blocks.

The deflection of the jet at the pool bottom occurs in both the up-and downstream directions. The importance of each of these deflections directly depends on the angle $\delta$ of the jet upon impact in the pool. As shown in Figure 13, based on Reich (1927), a theoretical approach for plane jets with initial discharge $q_{t o t a l}$ and thickness $D_{j}$ impinging on a flat plate relates the respective discharges $\mathrm{q}_{\text {up }}$ and $\mathrm{q}_{\text {down }}$ and thicknesses $h_{\text {up }}$ and $h_{\text {down }}$ by means of the cosines of the jet angle with the horizontal $\delta$ :

$$
\begin{aligned}
& \frac{q_{u p}}{q_{\text {total }}}=\frac{h_{u p}}{D_{j}}=\frac{1}{2} \cdot(1-\cos \delta) \\
& \frac{q_{\text {down }}}{q_{\text {total }}}=\frac{h_{\text {down }}}{D_{j}}=\frac{1}{2} \cdot(1+\cos \delta)
\end{aligned}
$$

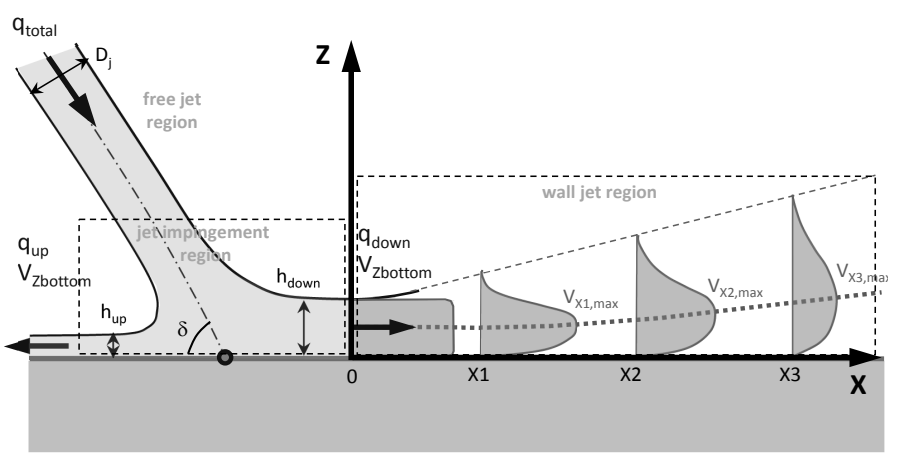

Figure 13: Plane jet deflection on a flat bottom (Reich, 1927)

Once the jet deflected, the wall jets may be characterized by their initial flow velocity $V_{\text {Zbottom }}$ and their initial thickness $h_{\text {up }}$ or $h_{\text {down }}$ at the point of deflection. Initiating from this singular location, the wall jets develop radially outwards following selfpreserving velocity profiles (Beltaos \& Rajaratnam, 1973 ) as given by the following equation: 
$\frac{V_{X, \max }}{V_{\text {Zbottom }}}=\frac{3.5}{\sqrt{X / h_{\text {down }}}}$

$\mathrm{V}_{\text {Zbottom }}$ depends on the diffusion angle of the impinging jet and on its development length through the water depth $\mathrm{Z}$. $\mathrm{V}_{\text {Zbottom }}$ continuously changes during scour formation. $\mathrm{V}_{\mathrm{X} \text {,max }}$ expresses the decay of the maximum cross-sectional jet velocity with the relative distance from the start of the wall jet (lateral distance $\mathrm{X}$ divided by the initial thickness of the deflected jet $h_{\text {up }}$ or $h_{\text {down }}$ ).

This decreasing velocity is of direct relevance to the potential generation of quasi-steady stagnation pressures at rock blocks protruding along the pool bottom. Several researchers have defined this pressure by means of an uplift pressure coefficient $C_{\text {uplift }}$ expressing the pressure as a percentage of the kinetic energy $\mathrm{V}^{2}{ }_{\mathrm{z}, \mathrm{m}} / 2 \mathrm{~g}$ of the quasi-parallel flow deviated by the block.

\subsection{Rock anchors}

The presence of rock anchors is accounted for in the different break-up modules in the following manner (Fig. 14):

1. CFM module: The additional pressure exerted by the anchors is accounted for in the computation of the fracture toughness of the rock mass.

2. DI/QSI modules: The presence of anchors is accounted for by an additional stabilizing force.

The latter additional forces are verified at each time step for a single block as well as for the multiple ranges of blocks concerned by the anchors. In case the anchors are needed to keep the block in place, the maximum allowable elastic steel stress is being verified. In case the stress field goes beyond, the block is considered being lost.

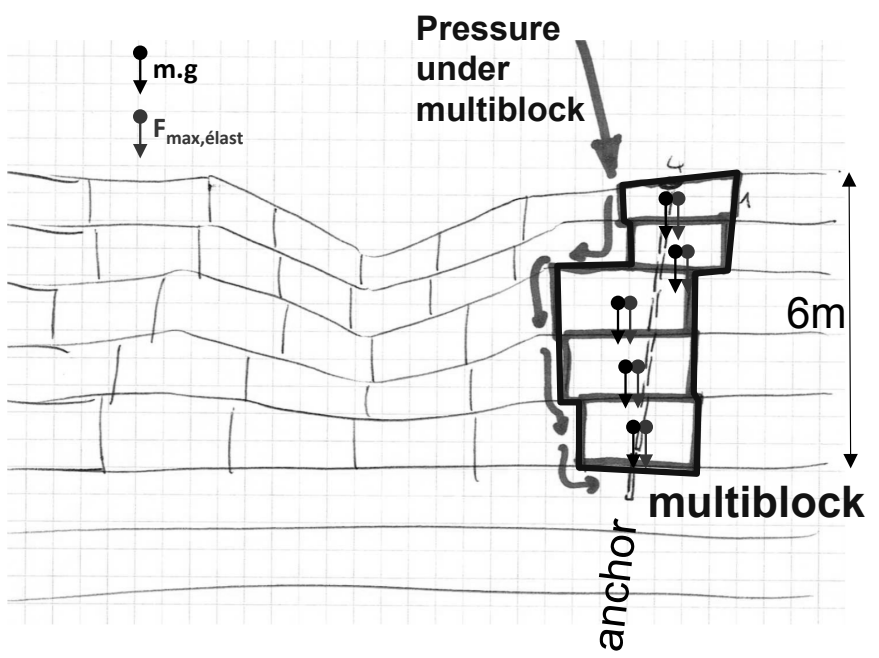

Figure 14. Additional forces induced by steel anchors on block uplift module of CSM.

\section{COMPUTED SCOUR POTENTIAL}

\subsection{Model calibration}

First, the numerical scour model has been calibrated against the scour formation observed since 1966 and by assuming that the observed damage is solely due to spillages and not to regularly used bottom valve jet dissipation. This has been performed for the left and right hand sides of the plunge pool separately, given the different scour vulnerability at these locations. Fig. 15 illustrates the calibration results along the right bank.

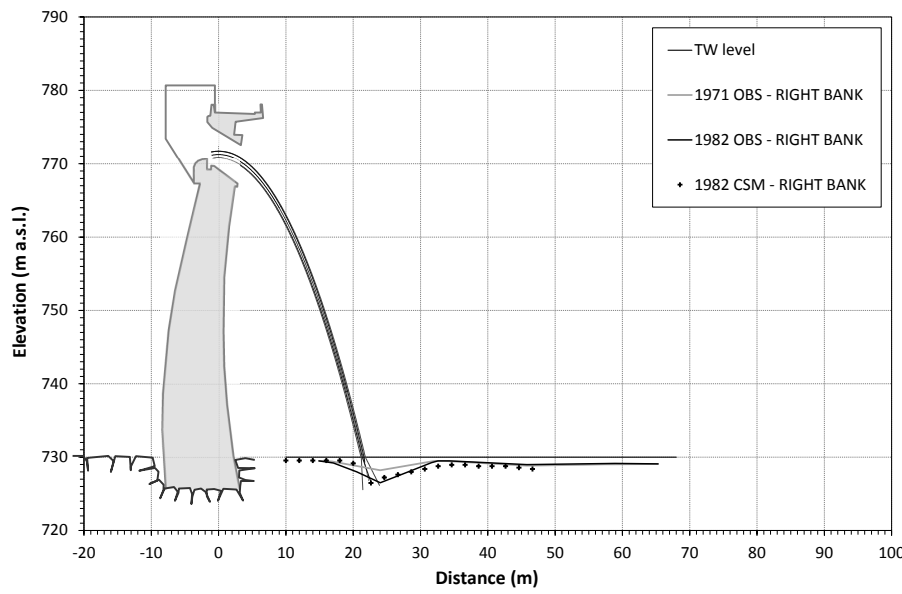

Figure 15. Calibration of CSM for the 1972-1981 period along the right bank of the plunge pool.

\subsection{Scour potential along left side of plunge pool}

A large number of numerical scour predictions have been performed by the CSM. The main parameters of the study were the UCS strength of the rock, the initial persistency (i.e. degree of fracturing in \%) of joints, the relative height of rock blocks (thickness of layers) and the presence of anchors.

The computations have been performed for HQ10, $2 \times$ HQ10 (succession of two 10-year floods), HQ100 and finally HQ1000.

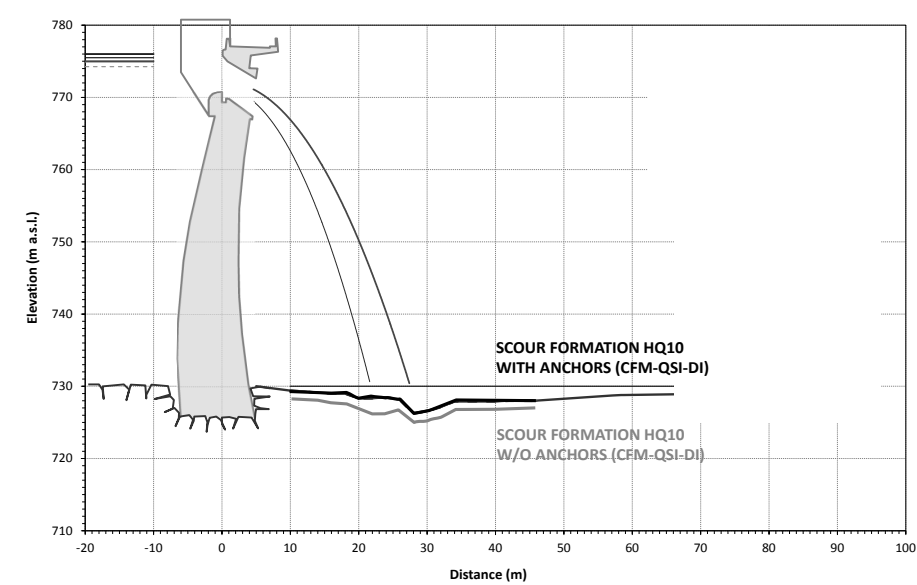

Figure 16. Scour potential along left bank following HQ10. 


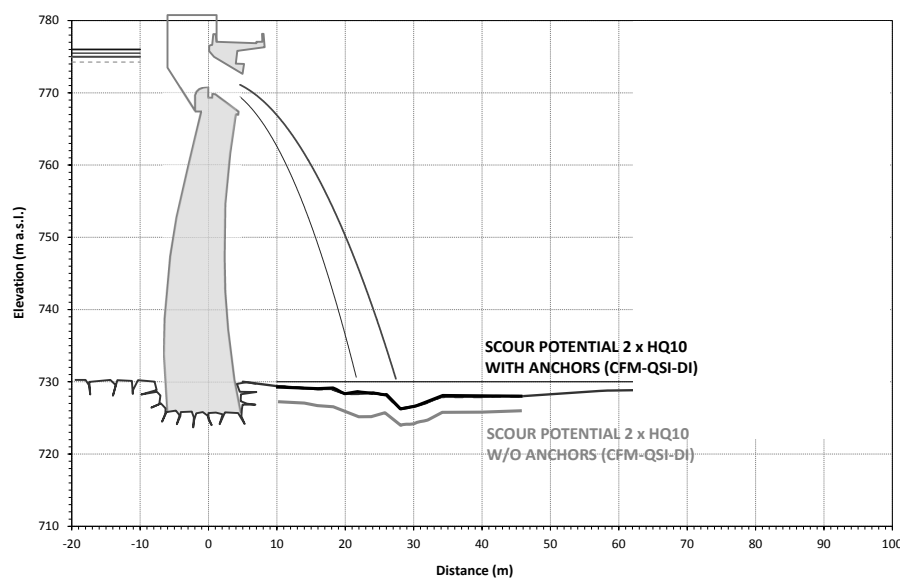

Figure 17. Scour potential along left bank following $2 \times$ HQ10.

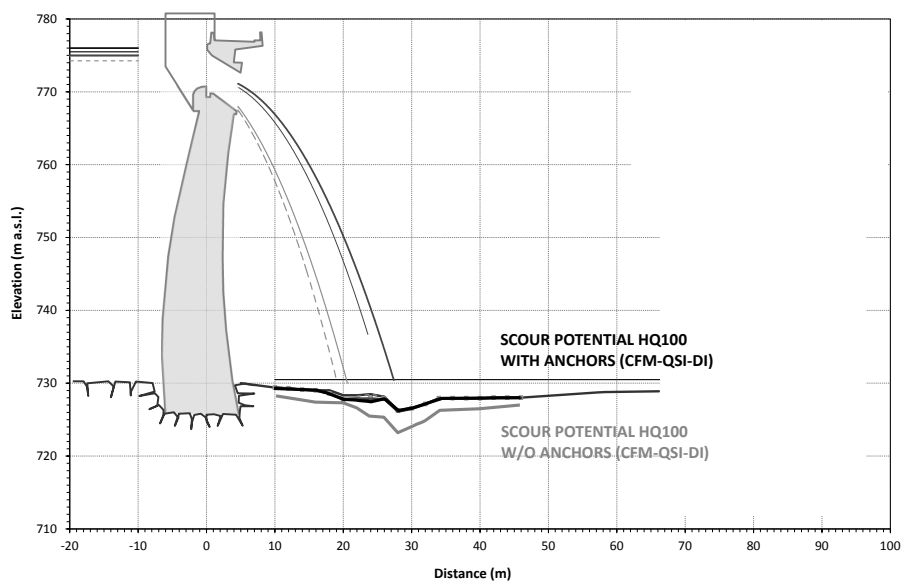

Figure 18. Scour potential along left bank following HQ100.

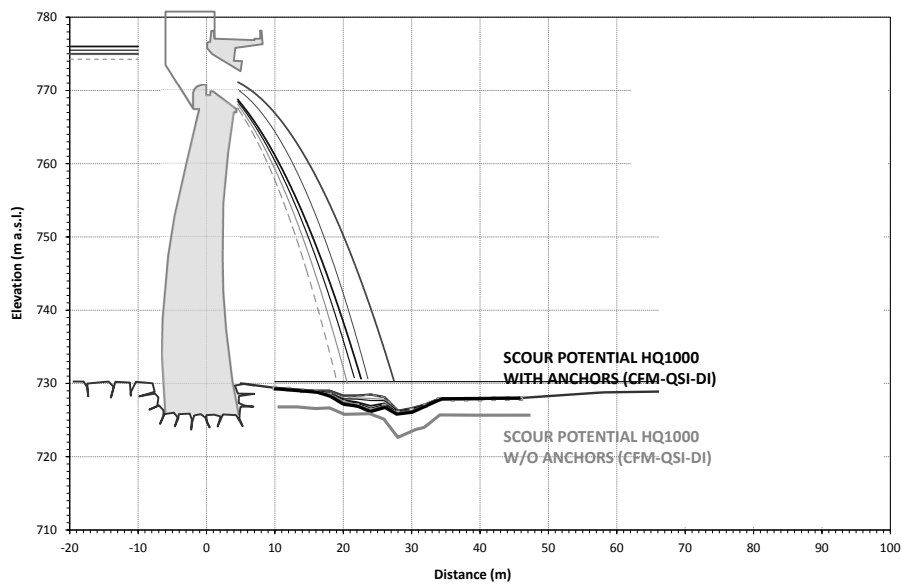

Figure 19. Scour potential along left bank following HQ1000.

Figs. 16-19 illustrate the scour potential for HQ10, $2 \times$ HQ10, HQ100 and HQ1000. The scour potential becomes significant for flood return periods of 100 years or more. Under such circumstances, scour regression towards the toe of the dam is initiated. Also, the rock anchors put in place in 2007 substantially reduce the potential for rock block uplift and ejection towards downstream, as well as the potential for scour regression towards the dam toe.

Fig. 20 summarizes and compares the scour potential for different flood return periods, with rock anchors in place.

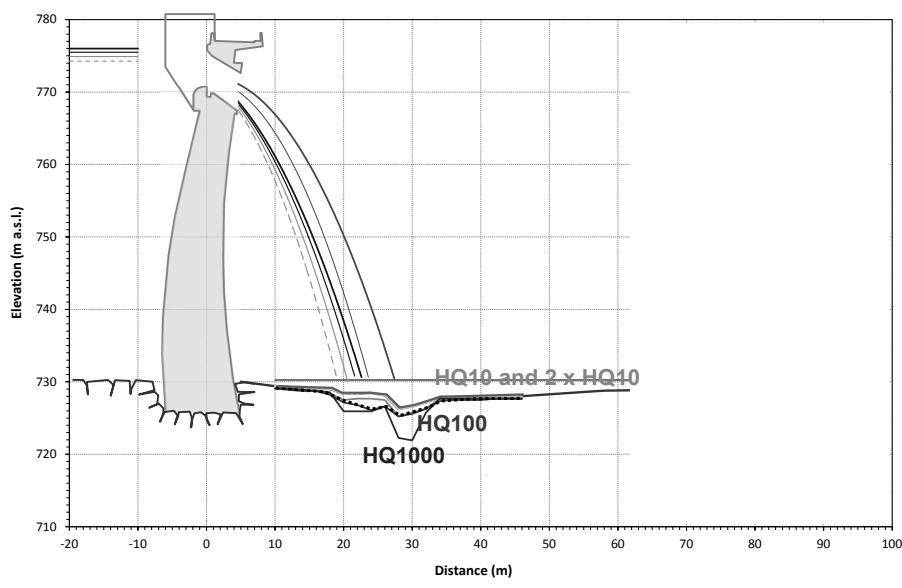

Figure 20. Comparison of scour potential along left bank following HQ10, HQ100 and HQ1000, WITH rock anchors.

\subsection{Scour potential along right side of plunge pool}

Similar to the left hand side of the plunge pool, a large number of numerical scour predictions have been performed by the CSM. The main parameters of the study were the UCS strength of the rock, the initial persistency (i.e. degree of fracturing in \%) of joints, the relative height of rock blocks (thickness of layers) and the presence of anchors.

The computations have been performed for HQ10, $2 \times$ HQ10, HQ100 and finally HQ1000.

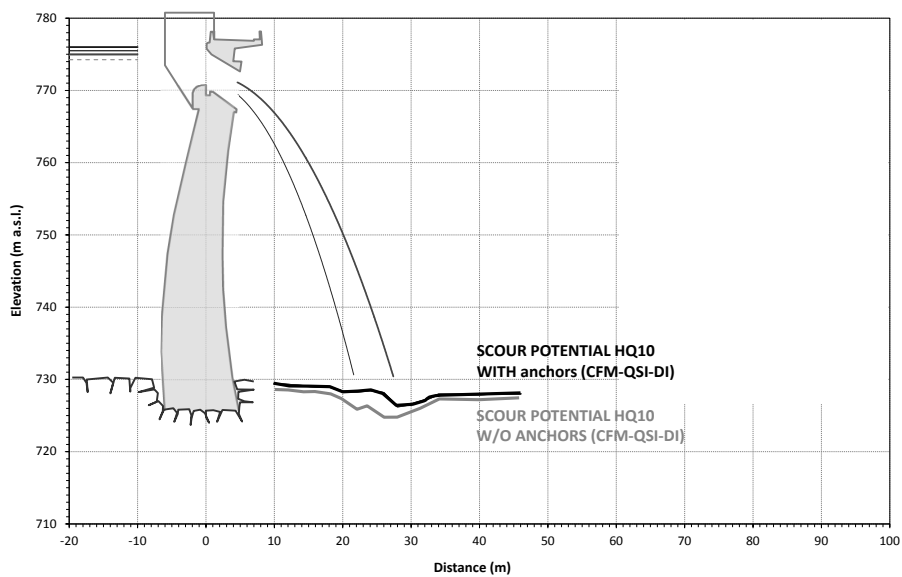

Figure 21. Scour potential along right bank following HQ10.

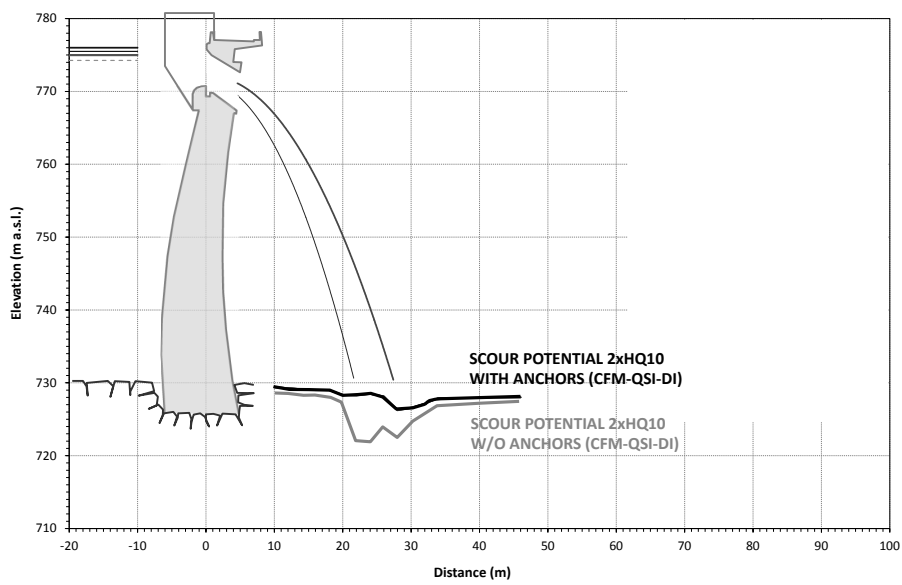

Figure 22. Scour potential along right bank following 2x HQ10. 


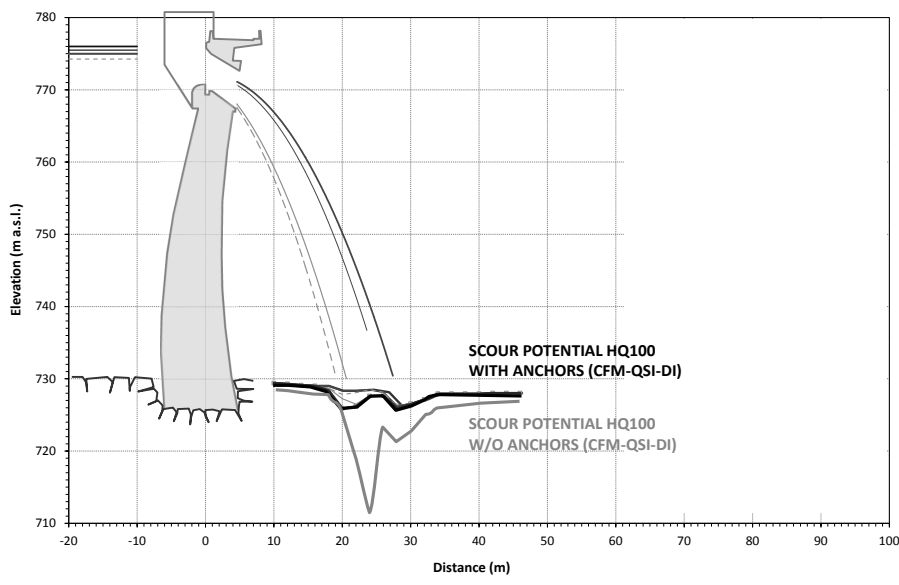

Figure 23. Scour potential along left bank following HQ100.

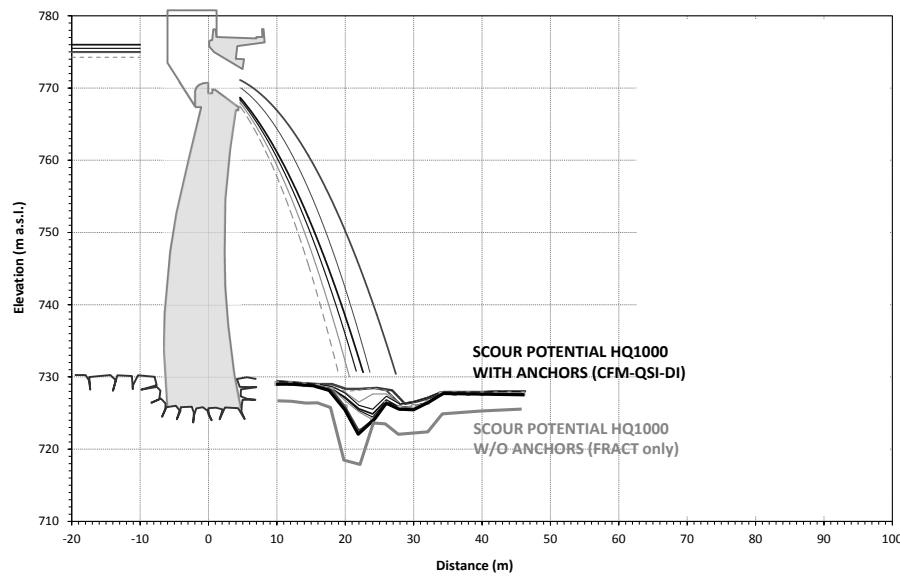

Figure 24. Scour potential along left bank following HQ1000.

Figs. 21-24 illustrate the scour potential along the right bank for HQ10, 2xHQ10, HQ100 and HQ1000. The scour potential becomes significant for flood return periods of 50 years or more, or also for two subsequently occurring HQ10 floods. This is mainly due to the much higher degree of fracturing on this side.

Under such circumstances, significant scour regression towards the toe of the dam is initiated. Also, the rock anchors put in place in 2007 substantially reduce the potential for rock block uplift and ejection towards downstream, as well as the potential for scour regression towards the dam toe.

Fig. 25 compares the scour potential for different flood return periods, with rock anchors in place.

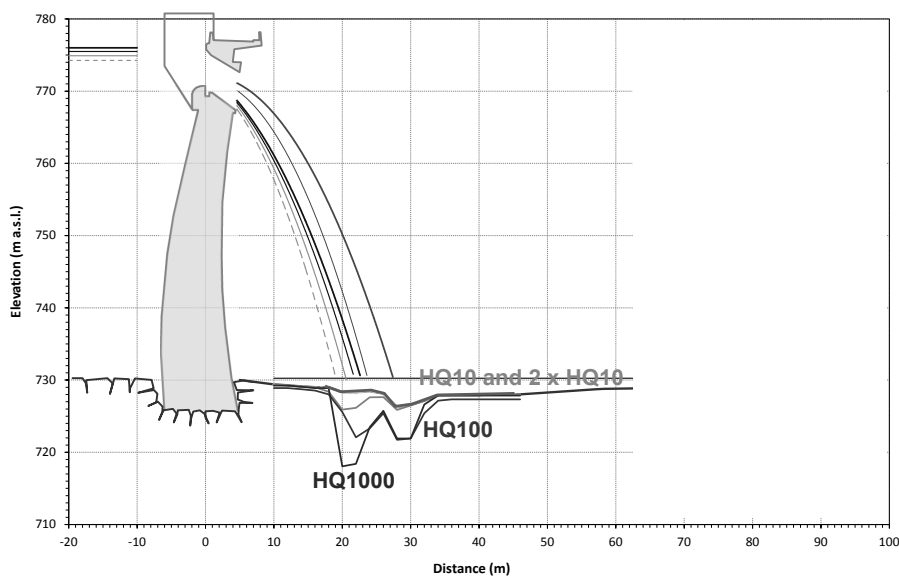

Figure 25. Comparison of scour potential along left bank following HQ10, HQ100 and HQ1000, WITH rock anchors.

\section{CONCLUSIONS}

Numerical computations of future scour potential at Laouzas Dam have been systematically performed for both the left and right sides of the plunge pool and for different flood scenarios. Additional scour formation may become significant starting from a 50-year return period flood along the right hand side, and starting from a 100-year return period flood along the left hand side of the plunge pool.

Downstream of Laouzas dam, the local stabilization by anchoring of the rock mass significantly reduces the potential for rock block uplift in the most critical areas of the plunge pool. The potential for scour regression towards the downstream toe of the dam is notably minimized during the transit of the project flood. Therefore, the objective of preventing damages to the downstream rock abutment of the central blocks of the dam is achieved.

If such anchors are able to significantly slow down the process of rock mass fracturing, they prove to be less efficient, on a long term basis, to effectively prevent the degradation of the rock. Based on past experience on similar plunge pools, anchored rock blocks may progressively decompose into smaller pieces and finally detach from the anchor.

EDF policy is to determine, by on site measurements, the evolution of the plunge pool after each significant spillage. On Laouzas site, it is anticipated that the scour model will be recalibrated based on the new data collected after the transit of the next significant flood, and predictions of scour potential refined. In case of damages whose consequences are judged prejudicial, appropriate remedial works will be carried out shortly after the spillage.

Local stabilization by anchoring of the rock mass may significantly reduce the potential for rock block uplift in the most critical areas of the plunge pool, and may reduce scour regression towards the dam toe.

\section{REFERENCES}

Beltaos, S.; Rajaratnam, N. 1973. "Plane turbulent impinging jets." Journal of Hydraulic Research, IAHR, Vol. 11, $\mathrm{N}^{\circ} 1$, pp. 29-59.

Bollaert, E. F. R. 2002. Transient water pressures in joints and formation of rock scour due to high velocity jet impact, PhD Thesis, Ecole Polytechnique Fédérale de Lausanne (EPFL), Lausanne, Switzerland.

Bollaert, E.F.R. 2004. "A comprehensive model to evaluate scour formation in plunge pools." Int. J. Hydropower \& Dams, 2004, 2004(1), pp. 94-101.

Bollaert, E.F.R. 2004. A new procedure to evaluate dynamic uplift of concrete linings or rock blocks in plunge pools, Intl. Symp. on Hydraulics of Dams and River Structures. Teheran. pp. 125-132.

Bollaert, E.F.R. and Hofland, B. 2004. The Influence of Flow Turbulence on Particle Movement due to Jet Impingement, 
2nd Scour and Erosion Conference, Singapore, November 2004.

Reich, F. 1927. "Umlenkung eines Freien Flüssigkeitsstrahles an einer ebenen Platte." Zeitschrift Verein deutscher Ingenieure 71 (8): p. 261-264.

Bollaert, E.F.R. 2012. Wall Jet rock scour in plunge pools: a quasi-3D prediction model, Intl. Journal on Hydropower \& Dams, 2012.

EDF EDTGG130267 C : Dossier préliminaire CTPBOH de modification substantielle du barrage du LAOUZAS, Etude géologique de synthèse.

EDF IH.MRCD.LAOUZ-EP.00007 A : Historique des déversements de l'évacuateur de surface et courbes de durée d'écoulement.

EDF IH.MRCD.LAOUZ-EP.00006 A : Trajectoire de la lame déversante issue de l'évacuateur de surface. 